\title{
Diablotexto
}

\section{Volver para desenterrar a los muertos. La encrucijada identitaria de Cristina Fallarás en Honrarás a tu padre y a tu madre}

\author{
Returning to unearth the dead. The crossroads of identity in Cristina Fallarás' \\ Honrarás a tu padre y a tu madre \\ IRIS DE BENITO MESA \\ UNIVERSITAT DE VALÈNCIA
}

\begin{abstract}
Resumen: Este ensayo se propone hacer un análisis textual y contextual de la novela Honrarás a tu padre y a tu madre (2018), de Cristina Fallarás, en la que la autora lleva a cabo una revisión identitaria impulsada por la investigación de su pasado familiar. Para el análisis, se relaciona en un primer momento la obra con otras de temática y contenido similar, también producidas en las últimas décadas. Asimismo, se realizará una aproximación a los usos de la autoficción y la docuficción que la obra propone, del mismo modo que se presta atención a la hibridación de géneros narrativos y textuales como el discurso periodístico, la autobiografía, la novela de investigación o el género policial. Por otra parte, el estudio se centrará en ciertos aspectos en los que la dialéctica entre el contenido de la obra y su disposición formal confluyen en una misma unidad de sentido, rasgo al que tampoco escaparán algunos elementos paratextuales.
\end{abstract}

Palabras clave: autoficción, docuficción, memoria, guerra civil, franquismo

Abstract: This essay aims to do a textual and contextual analysis of Cristina Fallarás' novel named Honrarás a tu padre y a tu madre (2018). For this purpose, we will first relate it with other works that adress similar contents and issues, which are also produced during the recent decades. Furthermore, we will make an approach to the uses of autofiction and docu-fiction in the novel. It will also be considered the use of different textual genres such as autobiography, jo urnalistic writing or fact-finding novel. Moreover, the study will be focused on certain aspects in which the dialectic formcontent is meaningful, including some paratextual components.

Key words: autofiction, docu-fiction, memory, civil war, francoism 
Si la construcción de nuestra memoria es una reelaboración que jamás podrá ser probada ni, por lo tanto, refutada, ¿qué vendría a ser la construcción de nuestra desmemoria? ¿Con qué piezas de Lego nos manejamos, criaturas, para montar aquellos recuerdos que se nos

\section{Introducción}

Bucear en la escritura de Cristina Fallarás es como montar un puzle. Vas buscando, aquí y allá, y poco a poco se va formando la imagen que aparecía en la caja, que no tiene exactamente el mismo tamaño ni resolución pero que es, a efectos prácticos, la misma imagen. En este caso la imagen de la caja es ella misma, la autora, que nos va dejando migas de pan para reconstruir retazos de su vida que en realidad ya ha contado antes en su perfil de Twitter, en una tertulia televisiva o en alguno de sus artículos de opinión. Son retazos que nos explican de dónde viene su discurso, pero sobre todo que le permiten hablar desde un Yo en mayúsculas, desde la vivencia, de una serie de problemáticas sociales candentes y que logran interpelar. No es un discurso, pues, puramente hedonista, sino en el que la autorreferencia es un lenguaje, un recurso para explorar una serie de temáticas que son también la herida de muchas otras personas. De forma explícita y en varias de sus obras, la autora se mueve en los límites de la no-ficción y crea una dialéctica entre el discurso activista que sostiene en medios y en redes, la performatividad de su personaje público y la ficcionalización o no de los hechos que narra. La novela aquí estudiada es una pregunta ante el espejo. Una pregunta que interpela a la identidad, un 'quién soy' con efecto boomerang. Con efecto boomerang porque la lanzas y, cuando te vuelve, tú crees que la vas a cazar al vuelo pero en realidad te acaba aterrizando en mitad de la frente.

Honrarás a tu padre y a tu madre (2018) es una obra que aborda, en lo que se refiere a la memoria histórica, cuestiones relativas tanto a la Guerra Civil como a la transición, si bien no se centra con tanta profundidad en el periodo histórico que comprende los años de dictadura franquista. Esta cuestión responde a disposición argumental de la novela así como a sus necesidades enunciativas y pragmáticas. Teniendo en cuenta la extracción generacional de la autora, puede deducirse que todos los sucesos que aparecen en la novela que son relativos a la Guerra Civil o las primeras 
décadas del franquismo no son fruto de un testimonio ocular propio, sino que están reconstruidos a través de testimonios de familiares o de personas cercanas, además de información recuperada por otros medios. Entre ellos, como es propio de esta clase de textos híbridos, aparecerán tanto elementos ficcionados como otros que son resultado de las investigaciones de la protgonista-autora. No obstante, en la tercera parte de la novela, que se ambienta en los primeros años de la transición, sí aparecerán una serie de escenas de las que la autora ha sido testigo ocular y que, por tanto, parten de la experiencia en primera persona.

En ese sentido, nos encontramos ante una obra que abordará varios periodos históricos, y asimismo varias experiencias generacionales, todas ellas orbitantes en torno al núcleo familiar de la protagonista.

\section{Puntales teóricos e historiográficos: tradición y elementos de la novela de la memoria en el contexto actual}

Es necesario, a la hora de hablar de este tipo de novelas que reconstruyen hechos relativos a la Guerra Civil y el franquismo, situarlas en contexto. Lejos de ser casos aislados o puntuales, pertenecen, a día de hoy, a una corriente que va ampliándose con el paso de los años; obras que, por otra parte, en muchos casos deudoras de novelas publicadas en las últimas décadas del siglo XX. Podemos recordar, al pensar en esta corriente, el trabajo de David Becerra titulado La guerra civil como moda literaria (2015) para hacernos una idea de cuántos títulos se han publicado recientemente en España con temática de la Guerra Civil. Es sintomático, en ese sentido, el título que elige Isaac Rosa para su reedición de Malamemoria (1999) en 2007: ¡Otra maldita novela sobre la Guerra Civil! (2014).

En esta línea, con frecuencia las obras comparten elementos relativos a la trama, a los personajes, al orden expositivo e incluso a la disposición formal. La novela de Fallarás, si bien no escapa a esa estela de rasgos comunes, también contiene otros que la singularizan. En relación con la tradición resulta ineludible recordar la obra Soldados de Salamina (2015) y del modelo que propone, puesto que la autoficción es asimismo el eje que estructura esta obra. Se trata de un recurso que permite crear un efecto de mayor veracidad, ya que 
utiliza significantes que remiten al plano de lo real. Sin embargo, se verá que los elementos que puedan ser dobles de los referentes extraficcionales se mezclan con otros que son puramente o mayoritariamente ficticios. Por otra parte, Honrarás a tu padre y a tu madre (2018) hereda muchos de los rasgos de la propuesta que realiza Antonio Muñoz Molina en su obra El jinete polaco (2016). En ella, la disposición tripartita se corresponde con la recuperación progresiva de la memoria familiar, proceso que va de la mano del de la revisión identitaria. Siguiendo el análisis de Oleza (2012), podemos decir que en la novela:

los personajes del presente y los del pasado viven inmersos en la historia, en la de la guerra civil y en la del franquismo, porque el presente y el pasado son inevitablemente históricos, pero viven la historia no en el espacio de lo público sino en lo privado, y buscan no la crónica de los acontecimientos públicos sino la verdad privada, la memoria del corazón, este lado de acá de la experiencia personal. Transitan por la historia plenos de privacidad (2012: 231).

Al hablar de autoficción resulta casi ineludible acudir a la obra de Alberca (2007), que se ha convertido en un referente de consulta obligatoria a la hora de abordar esta clase de novelas. Su obra El pacto ambiguo (2007), referenciada por buena parte de la crítica en este campo de estudio (Reisz, 2016; Sánchez Zapatero, 2011a, 2013; Martínez Rubio (2012a, 2012b, 2014, 2015), bebe a su vez de las teorizaciones de Lejeune (1994) relativas a los pactos de lectura. Concretamente, el autor concluye que de la posición intermedia entre los llamados "pacto ficcional" y "pacto autobiográfico", las "novelas del yo" (Alberca, 2007: 92), autoficcionales, se acogen a una especie de "pacto ambiguo" que asume carácterísticas de ambas. En ese sentido, Alberca definirá la autoficción como "una novela o relato que se presenta como ficticio, cuyo narrador y protagonista tiene el mismo nombre que el autor" (2007: 158). Por tanto, "el pacto ambiguo fija el horizonte de expectativas del lector en la referencialidad, en los hechos, y atenta conscientemente contra ese horizonte de expectativas al incluir en la narración procedimientos de ficción" (Martínez Rubio, 2014: 30). Además, en novelas del tipo que aquí estudiamos, esa estrategia comunicativa del pacto ambiguo forma parte del proyecto de la novela en su integridad. Recuperamos de nuevo la propuesta de Martínez Rubio cuando expone: 
La ambigüedad no solo supone la hibridez de elementos de realidad y de ficción dentro de un texto; ni tampoco supone solamente una combinación de técnicas escriturales distintas, como la mezcla de un discurso periodístico, ensayístico o novelesco. La ambigüedad presenta una estrategia narrativa referencial y ficcional al mismo tiempo, no de forma intermitente y fragmentada, sino de forma simbiótica e integral. (2015: 134)

En esta encrucijada de lo ambiguo, por tanto, cobrarán una relevancia especial las ambivalencias que plantean dudas entre la ficción y "lo real", por un lado, y acerca de la identidad de ese sujeto enunciador del relato que se mueve a caballo entre el protagonista y el propio autor. ¿Quién es ese individuo que nos habla desde una novela, pero que comparte identificador onomástico con el autor? Desde que la obra se presenta, a nivel paratextual, como una novela, no es aceptable asociar la enunciación con la del yo autobiográfico, si bien la fácil asociación entre protagonista y autor nos avisará de que tampoco es del todo coherente adscribirlo a la categoría del yo ficcional (Alberca, 2007: 204).

En la novela de que se ocupa este análisis vemos cumplidos todos los rasgos que Alberca propone. De este modo, surge la gran pregunta ¿cuáles son los elementos ficcionados y cuáles los tomados, como si de un reportaje se tratara, de una investigación real? En el caso de Cercas, por ejemplo, en su obra puede apreciarse que, mientras que la investigación relativa a Sánchez Mazas se corresponde con una investigación real llevada a cabo por el autor, otros elementos y personajes pertenecen al plano de lo ficcional. En el caso de Honrarás a tu padre y a tu madre (2018) esta distinción, esta tarea de deslindar lo factual con lo ficcional en que el lector inevitablemente se embarca, se torna algo más compleja. Todos los personajes, acciones y motivos argumentales podrían ser fruto de una investigación real de la autora sobre su familia. Esta búsqueda del grado de ficcionalización se dificulta también desde el momento en que la autora se pronuncia públicamente ${ }^{1}$ para confirmar que prácticamente nada de lo que aparece en el texto es una construcción ficcional (Clemot, 2018).

\footnotetext{
1 Seguimos la tesis de Oleza que, empleando las teorías de Searle sobre los actos de habla, afirma que "el criterio que permite distinguir si un texto es o no una ficción es la intención ilocucionaria (o no ilocucionaria) de su autor". En el caso de esta novela, nos encontramos ante el problema de una contradicción: una autora que afirma que no se trata de ficción, por un lado, y el formato editorial de una novela, por otro. De ahí, acaso, la naturaleza del pacto ambiguo.
} 
¿Qué queda entonces, de ficticio, si hasta la propia autora confirma que prácticamente todo pertenece al orden de lo documental? ¿Son suficientes los paratextos y algunos elementos puntuales para hacer pasar al texto por el aro de lo ficcional? Con todo, no debe pasar por alto, más allá de que los contenidos que se presentan sean fruto de una investigación real de la autora, que los hechos que presenta sí sucedieron. Sin embargo, hay algo de ficción acaso transversal en la disposición del relato, en la forma enunciativa. Su ejemplo más claro tal vez sean las escenas que reproducen diálogos, sobre todo aquellas que la autora no ha podido presenciar, situadas temporalmente en la juventud de sus abuelos, o aquellas en que la narración se focaliza en la subjetividad de personajes para disertar sobre sus emociones. Muestra de ello podrían ser los pasajes que ahondan en el pensamiento de su abuela Presentación en su juventud, con quien la protagonista, como podemos saber con la lectura de la obra, nunca tuvo una relación lo suficientemente estrecha como para conocer sus sentimientos y emociones.

Sin embargo, tal vez tratar de deslindar tan minuciosamente la ficción y la "verdad" no sea un objetivo tan pertinente, y acaso deberíamos desplazar el foco de atención al valor pragmático de la obra, a la intención comunicativa y a la propuesta de sentido que esta configura. En ese sentido, suscribo las palabras de José Martínez Rubio cuando afirma que:

\begin{abstract}
El problema de la "verdad", si consideramos como válido el cambio que la pragmática operó en los estudios literarios, no reside tanto en las formas de los propios discursos, sino en la voluntad que autor y lector reconocen en ellos. Los trabajos de John Searle $(1975,1979,1983)$ pusieron el acento en la "intentionality" de la obra, pero no lo hacía privilegiar la interpretación autorial por encima de cualquier otra, sino para entender el funcionamiento de los textos, su circulación, su interpretación y su incidencia atendiendo a criterios formales, pero también de situación, contexto, [...] formato [...] y demás elementos que condicionan la lectura de una obra. (Martínez Rubio, 2014: 2829)
\end{abstract}

En una línea similar, en otra obra de 2015, Martínez Rubio reflexiona en torno a la teoría de los "marcos cognitivos" de Lakoff (2006) para hablar de cómo funcionan los relatos de investigación de autor, en los que entraría la ya citada obra de Cercas, en consonancia con los límites entre lo ficcional y "la verdad". Esto le sirve de soporte, además, para ofrecer una definición específica de este tipo de textos, que renuncia a encajar dentro de otros géneros preestablecidos. Así, concluye que 
ni siquiera consideraré la investigación de autor como un género o subgénero de la novela negra o de la novela de no ficción, sino como un procedimiento narrativo y pragmático sobre la representación del pasado y del presente, con una estética realista posmoderna que se fundamenta sobre un pacto ambiguo de referencialidad, donde lo ficticio y lo auténtico se entremezclan en un terreno ambivalente y verosímil. (2015: 111)

En relación con el empleo de la autoficción se desprende también otro rasgo narrativo, presente en esta novela, que tiene que ver con los géneros textuales y discursivos, y que remite de nuevo a Javier Cercas y al modelo de novela del yo que propone Soldados de Salamina (2015). Como se ha dicho, Honrarás a tu padre y a tu madre (2018) se presenta como una novela, es decir, nos permite reconocerla como tal a partir de los paratextos, y además es una historia que está lo suficientemente narrativizada o novelada para aceptar esa parte que correspondería al "pacto de ficción". Sin embargo, no resulta difícil rastrear las huellas del ejercicio del periodismo en la forma en que se plantea la investigación, y también en la incorporación de elementos que remiten al plano extraficcional.

Del mismo modo que ocurre con Javier Cercas, Cristina Fallarás es periodista, y este plano profesional en absoluto corre por una vía alejada de su actividad como escritora de novelas. Lejos de plantear una delimitación clara entre sus producciones periodísticas y literarias, la autora las aborda como diferentes formas de explorar, de comunicar, que pueden construirse en diálogo. Esto hace que textos que se presentan como novela tengan, por ejemplo, rasgos de crónica periodística o incluso de documental, como es el caso de Honrarás a tu padre y a tu madre (2018). No obstante, no es algo que suceda solo en esta obra, sino que podemos ver lo mismo en otras de sus publicaciones. Por ejemplo, en A la puta calle. Crónica de un desahucio (2013), aparece el efecto contrario. Se trata de un texto que, tanto a nivel paratextual como en lo relativo a la intención declarada de la autora, se reconoce como autobiográfico y no como obra de ficción y, en cambio, en la disposición narrativa y la reconstrucción de ciertas escenas y diálogos pueden rastrearse las huellas de una mano que maneja la materia textual y la narrativiza. Con ello, la idea que se desprende es que los límites entre el ejercicio del periodismo y la escritura literaria están intencionalmente difusos y que, además, son un rasgo distintivo de la escritura de la autora. 
En una entrevista de 2014, que concede a propósito de la publicación de su novela Las niñas perdidas (2011), comenta que el argumento central de la misma proviene de una noticia real que recibió mientras trabajaba en la redacción de un periódico, un caso que le impidieron seguir investigando y, por tanto, publicar. Con este ejemplo, vemos cómo cobra sentido la voluntad de servirse de la vía literaria para enfrentar conflictos, problemáticas y miedos sociales cuya exploración el periodismo limita en determinadas circunstancias. En esa línea, puede pensarse en esa hibridación de periodismo y literatura como un rasgo de este tipo de literatura actual que está particularmente interesada en representar sucesos de la realidad más inmediata, a través de distintas propuestas estéticas.

Del empleo de la autoficción y su voluntad de crear un determinado efecto de verdad se desprende, en algunos casos, el concepto de docuficción, ampliamente estudiado por críticos como José Martínez Rubio (2015), Christian Von Tschilschke y Dagmar Schmelzer (2010), entre otros. A lo largo de las páginas de Honrarás a tu padre y a tu madre (2018) aparece incorporada toda una serie de fotografías, tanto de personas como de espacios, aportadas por ese sujeto ambiguo del discurso que es la protagonista-narradora-autora. Estos documentos gráficos están colocados en diferentes puntos de la narración, de forma que contribuyen a la voluntad argumentativa del relato y completan la propuesta de sentido de la obra. Además, su necesidad queda explicitada por la propia protagonista, quien afirma: "las fotografías son los únicos recuerdos que no mienten. Que no se inventan. [...] Afortunadamente, quedan las fotografías" (2018: 152-153). A modo de ejemplo, prestemos atención a cómo la primera parte de la novela se cierra con la fotografía de la tapia donde fusilaron al Félix Chico, con lo que se relaciona la muerte del abuelo con una imagen de ausencia, que muestra un lugar vacío, tan solo un muro, que es a la vez el punto de enclave con el momento del asesinato.

El recurso de mostrar como complemento del contar contribuye, a todas luces, a generar un "efecto de autenticidad" (Martínez Rubio, 2015: 138) que tiene que ver con la verosimilitud de este tipo de novelas. Se trata, dentro de esta dialéctica narrativa ambigua, de una "ilusión referencial o de veracidad [que] ayuda a crear un universo verosímil, necesario para la novela realista, 
sea cual sea su matiz concreto" (Martínez Rubio, 2015: 140). Así, la novela de Fallarás complementa la estrategia autoficcional con elementos docuficcionales y rasgos de la investigación periodística; de todo ello resulta una narrativa de signo realista (Oleza, 2012: 193-208; 1996) que consigue crear un efecto de lo auténtico como vía de inteligibilidad de la historia que cuenta.

Tras dar un repaso a los conceptos teóricos que permiten situar la obra en su contexto editorial, así como en relación con una tradición y otras obras similares publicadas en los últimos años, en el siguiente apartado se tratará de hacer un análisis en mayor profundidad de la obra, prestando atención al modo en que funciona su propuesta de sentido por las vías formal y argumental.

\section{Un acercamiento a la propuesta narrativa: de lo formal a lo argumental y viceversa}

En general, la obra trata la manera en que su protagonista intenta recuperar una fracción de la historia de su familia que se encuentra vacía en su memoria; concretamente, la de sus abuelos. En la reconstrucción de la historia familiar, tiene una relevancia considerable la disposición de la obra en tres partes, cada una de ellas con la suficiente autonomía narrativa como para detenerse en una aproximación específica. Así, a continuación, señalaré las que considero las cuestiones más significativas a la hora de comprender su funcionamiento y significado, evitando glosar el argumento y poniendo el foco en aquellos rasgos que sirven al análisis global de la obra. A grandes trazos, las partes primera y segunda se centran en reconstruir el pasado de sus abuelos, respectivamente, paternos y maternos. La tercera parte, en cambio, que narra fundamentalmente acontecimientos fechados en la infancia y la juventud de la protagonista, tendrán como motivo central la reflexión sobre la propia identidad y la revisión de toda una serie de cuestiones relativas a la institución de la familia.

Cabe tener en cuenta que, de forma paralela a esta disposición temática, las tres partes cuentan a su vez con capítulos intercalados situados en el presente de enunciación de la protagonista. En ellos se narra un viaje itinerante: la protagonista ha salido de su casa sin rumbo, iniciando un camino incierto que se presenta como paralelo al ejercicio de escritura. Al ejercicio de 
escritura y no al proceso de investigación, un rasgo que aleja a la obra de la tradición de novela de la memoria autoficcional de investigación (Martínez Rubio, 2015). Es decir, en esta autoficción la protagonista no narra el proceso de investigación, sino que los datos, la información, se le presentan al lector en un punto en el que la protagonista ya ha concluido dicho proceso. Con ello, el lector no acompaña a la protagonista en su indagación y progresivos descubrimientos, sino que emprende la lectura y asimilación de los datos siguiendo un orden del relato dispuesto a posteriori por la protagonista. No conocemos, por tanto, el orden o la forma en que esta recopiló la información que aparece ni tampoco la manera en que la consigue, sino que hallamos directamente una historia reconstruida.

Sí se encuentran, con todo, algunos capítulos breves que dan cuenta, a modo de recuerdos recientes, de momentos puntuales del proceso de las averiguaciones, pero de ninguna manera este es el eje vertebrador de la narración. En ese sentido, las similitudes que la obra pueda tener con ciertos elementos del género policial no pasan tanto por reproducir la pesquisa de la protagonista, sus dudas e impedimentos en la búsqueda de información, como con la forma en que el lector averigua, conjetura, realiza hipótesis y queda prendido de un cierto suspense a medida que avanza dicha lectura.

Este presente enunciativo, en que la protagonista emprende una suerte de peregrinación itinerante mientras escribe la historia, se muestra desde las primeras líneas de la novela casi a modo de declaración de intenciones. Con ellas, además, propone al lector el pacto ambiguo de la autoficción desde el primer momento. Las palabras que abren en primer capítulo son claras al respecto: "me llamo Cristina y he salido a buscar a mis muertos. Caminando. Buscar a mis muertos para no matarme yo. ¿Para vivir? No estoy segura. Convocarlos, dialogar con mis muertos" (2018: 11).

En lo que respecta al eje temático de la primera parte, la memoria de sus abuelos paternos, el hecho fundamental es el fusilamiento del abuelo paterno Félix Fallarás, "el Félix Chico", en diciembre de 1936 en Torrero, Zaragoza. A lo largo de los diferentes capítulos que tratan de reconstruir su historia se verá que la narración gira en torno al episodio del fusilamiento; así, aparecerá cómo fue detenido y cómo se lo fusiló horas después. De esta serie de capítulos que 
giran en torno a Félix Fallarás, trasluce una carencia de información, de material narrativo, que es fundamental para el análisis de esta primera parte.

Las escenas narradas giran en torno al acontecimiento del asesinato. Hay poca sucesión temporal en términos lineales, ya que solamente se narra desde unas horas antes de su detención hasta el día siguiente, en que su mujer y su madre tratan de informarse acerca de la detención y se les comunica que Félix ya ha sido fusilado. La historia de este antepasado, por tanto, se reconstruye a partir de muy pocos datos, y la narración se dilata temporalmente y se recrea en torno a unas pocas escenas como la de Presentación, mujer de Félix, esperando junto al fuego la vuelta de su marido, a quien jamás volverá a ver. De hecho, la propia narradora reconoce explícitamente y hace partícipe al lector de esa carencia informativa. En el punto en el que se presenta la escena del fusilamiento, leemos: "Nada sé yo del hombre que va a morir. Hasta su muerte hicieron desaparecer. No conocí al Félix Chico. No existe su historia. Hasta eso le negaron".

Además de reconocer la carencia informativa, estas palabras apuntan algo más allá y anuncian una de las reflexiones principales de la obra: la construcción de un relato de vencedores que instauraría el silencio y el olvido sobre los vencidos en las generaciones siguientes. Respecto a ello, encontramos uno de los pocos pasajes en que se reproduce el proceso de investigación de la protagonista, narrado en un pasado próximo, anterior al citado viaje que está realizando en el presente. Este tiene que ver con el momento en que tiene la primera noticia sobre el lugar del fusilamiento de su abuelo. La vía de acceso a esta información, con todo, no será ningún vínculo familiar; nadie de la familia le ha contado nunca los sucesos relativos al asesinato de Félix Fallarás. Será mediante una página web de recuperación de la memoria histórica como Cristina encontrará por fin la fosa común con una inscripción que reza el nombre de su abuelo. En ese preciso instante en que se opera el reconocimiento, el impacto emocional se refleja también en plano formal del relato:

Fusilado en las tapias del cementerio de Torrero 13489.

Fusilado en las tapias del cementerio de Torrero 13489.

Fusilado en las tapias del cementerio de Torrero 13489.

Fusilado en las tapias del cementerio de Torrero 13489. 
Fusilado en las tapias del cementerio de Torrero 13489.

Fusilado en las tapias del cementerio de Torrero 13489.

Fusilado en las tapias del cementerio de Torrero 13489.

JODER: Fusilado en las tapias del cementerio de Torrero 13489.

JODER, JODER, JODER: Fusilado en las tapias del cementerio de Torrero 13489.

¿Qué significa ese 13489? ¿El asesinado número 13.489? ¿Es eso? ¿Qué coño significa ese número? ¿Qué coño un abuelo que, hasta un segundo antes de leer su nombre, no existía? (2018: 84)

Teniendo en cuenta la actitud afiliativa que mostraba la protagonista al hablar de la construcción de silencio que opera el relato hegemónico sobre la Guerra Civil, podemos ver que esta se combina y alterna con la actitud filiativa; el motivo de la búsqueda de la historia familiar, con todas las connotaciones afectivas que ello conlleva, no es incompatible con la actitud afiliativa. Cristina muestra reiteradamente que sabe reconocer lo que hay de social, de colectivo, de público, en su historia familiar y, en ese sentido, recupera "la dimensión pública de lo privado", devuelve "lo individual al seno de la realidad colectiva y de la historia" (Oleza, 1997: 3). El modo en que se clausura uno de los últimos capítulos de la primera parte da cuenta de una postura militante que se va a mantener a lo largo de toda la narración:

\footnotetext{
Maldigo, pues, a quienes matan la memoria. Maldigo a los oscuros constructores del silencio. Dos existencias le negaron a Félix Fallarás. De un tiro echaron su vida contra la tapia y al suelo sediento de Torrero. Después, se cubrió con silencio su memoria y, ay, fue nada. (Fallarás, 2008: 85-86)
}

Hacia el final de la primera parte podremos ver, además, a una figura que aparece fugazmente al inicio: el Alférez, el Coronel, Pablo Sánchez (Juárez); el abuelo materno de la protagonista. Este, casualmente, también se encontraba en Torrero el 5 de diciembre de 1936, y presenció precisamente el fusilamiento de Félix Chico. A partir de este momento encontraremos una gran oposición en estos dos personajes, los dos abuelos. Los rasgos que distinguen a ambos son diversos: su extracción social, su posición de clase, presenta por un lado a un humilde trabajador rural, mientras que el Alférez será una joven promesa del ejército franquista, descendiente de Benito Juárez y con un futuro que le augura ascenso social dentro del régimen franquista.

Este personaje nos permite adentrarnos en la segunda parte de la novela, a lo largo de la cual se desarrolla la historia de la familia materna de la protagonista. Así, se elabora toda una genealogía que va desde sus bisabuelos 
hasta el nacimiento de su propia madre. Podemos ver cómo se reconstruye multitud de escenas, lugares, tramas personales y una cantidad considerable de diálogos. Una de las figuras principales será la del ya mencionado abuelo materno, el alférez. Veremos, por otro lado, la historia de la abuela materna y cómo las de ambos confluyen. En definitiva, lo más relevante de esta parte, respecto a la temática de la memoria histórica y su recuperación, no está explícitamente dicho en la novela. Esta segunda parte, si se compara con la primera, tiene unos rasgos y una disposición narrativa muy diferentes. $\mathrm{Si}$ respecto a la primera decíamos que se recrea, casi de forma circular, en el acontecimiento del fusilamiento como único punto de enclave con la vida y la historia, con la memoria del abuelo paterno, en esta segunda parte ocurre lo contrario.

La abundancia de información y de detalles, pese a que se presente igualmente como el resultado de una investigación, de un rastreo de memoria, muestra precisamente el éxito de ese rastreo, es decir, el fácil acceso al recuerdo. En ese sentido, el silencio que envuelve a la historia de Félix Chico no es el mismo, o no es de la misma clase, que el que hay sobre la historia de la familia materna, sobre el alférez y su mujer, los abuelos maternos de Cristina. Esta parte supone un capítulo cerrado, también a nivel de contenido. Es decir, la historia se cierra y se satisfacen las necesidades de búsqueda.

Una vez alcanzado el límite de lo posible en la reconstrucción de los hechos de los dos lados de la familia, empezará una tercera parte en la que progresivamente la protagonista será ya la figura central.

Así pues, esta tercera parte se compone de recuerdos en primera persona, momentos tomados de la memoria de la protagonista, de hechos que esta ha vivido o de escenas reconstruidas a partir de sus recuerdos. Esta será asimismo la parte más reflexiva, que se corresponde de forma más desarrollada con la revisión de la memoria individual y con la reconstrucción de la identidad. Es significativo que este tercer bloque empiece con una escena protagonizada por el coronel, el abuelo materno, ya en su vejez, en frente de una grabadora dispuesto a confesar lo más oscuro de su pasado. Él, que ha sobrevivido a la guerra y al franquismo por pertenecer al bando vencedor, tiene la posibilidad de contar su historia, mientras que por parte del otro abuelo lo 
único que queda es la ausencia, la incógnita y el desconocimiento.

Poco después, en un capítulo muy breve, se cuenta un acontecimiento que el lector ya puede imaginar: finalmente, el hijo de la pareja que protagoniza la primera parte se casa con la hija de la que protagoniza la segunda. Desde el presente, Cristina observa con estremecimiento la foto de la boda de sus padres, con una perspectiva totalmente distinta a la que había tenido hasta entonces (Fallarás, 2018: 154). Este hecho azaroso es uno de los puntos claves del argumento, que sirve sin duda para captar la atención del lector y generar intriga, pero que de la misma forma también plasma, a través de una ironía trágica, las correspondencias entre las esferas pública y privada; víctimas y victimarios de un suceso concreto, vencidos y vencedores, acaban por formar parte de la misma familia. En la ya citada entrevista realizada por Fernando Clemot (2018) a la autora, Fallarás insiste en lo significativo de este acontecimiento para la concepción de la propia identidad: "¿Quién soy? Soy la hija de un padre que se calló el asesinato de su padre. La hija de aquel que se quedó a vivir en la casa de los asesinos de su padre".

En los capítulos que siguen, ya acercándose al final de la obra, la protagonista hará un repaso retrospectivo de sus recuerdos de infancia y adolescencia. En ellos, solamente está presente su familia materna, una familia adinerada y bien posicionada en el régimen militar franquista, conservadora y católica. Cristina, entonces, revisa toda la educación que ha recibido, se cuestiona por qué nunca se le mencionó el asesinato de su abuelo paterno y por qué nunca pasó tiempo con su abuela materna. A esta última sí la conoció, pero en cambio, resulta curioso comparar a la abuela materna con la paterna, igual que ocurría con los abuelos.

A Presentación, la mujer del abuelo que fue fusilado, se extiende el mismo silencio que lo envuelve a este, aun estando viva. La otra, en cambio, de nombre María Josefa, está presente en todos los recuerdos felices de su infancia y tiene un peso importante en su construcción identitaria:

Mis recuerdos de mi abuela María Josefa, la Jefa, no pueden ser narrados inocente, objetivamente. Reconozco, cabrona y etcétera, mi debilidad por María Josefa. Ella fue quien me enseñó a bailar el charlestín, quien apoyó mis huidas, quien me puso, sin conciencia ni intención más allá del capricho, el espejo en que me miro. (2018: 206) 
En este ejercicio de reflexión que estructura la última parte de la obra, el personaje llega a relacionar un determinado modo de vida con el lenguaje, con los signos y los referentes de los vencedores. En ese sentido, el hecho de que ella creciera en un ambiente lujoso y acomodado económicamente no solo irá ligado a una determinada ideología, sino que además formará, para ella, parte de esa construcción de victoria del bando franquista:

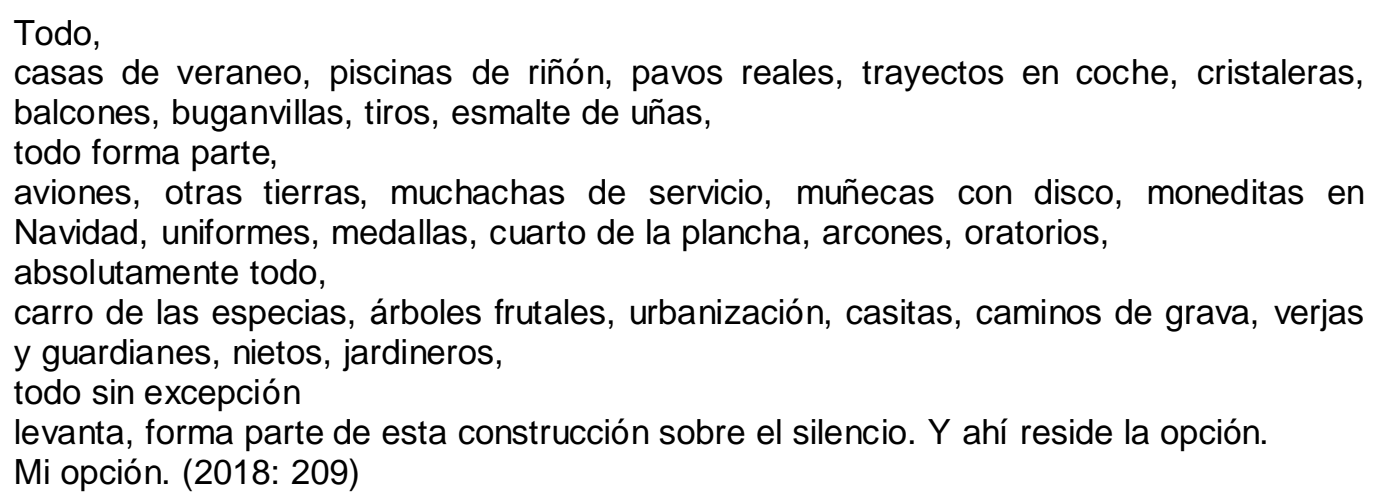

Esta asociación, lejos de ser casual, permite realizar una lectura de vencedores y vencidos en términos de clase; mientras que el lujo más ostentoso configura el telón de fondo de una familia de victoriosos vencedores, la pobreza y la miseria caracterizan a aquellos que lo perdieron todo, incluyendo la vida. A lo largo de varios capítulos, podemos constatar que la protagonista se crio con sus abuelos maternos, mientras que a su abuela Presentación la veía un par de veces al año, en que la abuela María Josefa regalaba a esta su ropa usada. Los recuerdos de la infancia de Cristina, en relación con sus dos abuelas, están atravesados por esta lectura de clase que es el vértice de la oposición entre ambas, como asimismo también lo está la revisión autocrítica que la protagonista hace de ellos:

\footnotetext{
Yo conocí a Presentación Pérez, mi otra abuela, la viuda, como una auténtica hija de puta. Yo auténtica hija de puta, no ella. ¿Cómo si no?

Nos regalaba pases para ir al cine, pero nosotras, que éramos imbéciles crías hijas de puta, creíamos que el cine se pagaba solo, que llevar un bono era triste y marrón. Las cosas gratis estaban cubiertas de polvo, las cosas con bono eran además repugnantes y había que tocarlas el menor tiempo posible. [...] Las cosas no compradas apestan. Ese tipo de hija de puta. (2018: 203)
}

En esta tercera parte aparecerán de nuevo recuerdos del pasado reciente de Cristina, que hacen referencia al proceso de investigación que en su día llevó a cabo. En ellos, se da cuenta del silencio que recibió a través de 
esa familia materna cuando decidió recabar información acerca de su pasado. Un constante silencio, y disuasiones, sobre todo por parte de su madre. Además, utilizando como pretexto la relación de filiación, los vínculos familiares, se muestra la dificultad de no retratar a los sujetos a partir de las relaciones personales y afectivas para poner en primer plano la dimensión política de sus actos. La protagonista, pese a conocer el pasado de su familia materna y su rol de victimarios durante la guerra y el franquismo, confiesa no poder dejar de recordarlos con el cariño que se tiene a unos abuelos, lo cual supone un conflicto interior.

El último fragmento es una síntesis de los contenidos y a la vez una clausura; nos muestra que, al terminar el proceso de búsqueda, se cierra una herida y se completa el proceso de reconstrucción identitaria. Es también el final de ese viaje que se iniciaba al principio de la novela.

\footnotetext{
El silencio se combate, antes, en la familia. El primer silencio que se combate es el íntimo, el familiar. Si ese permanece, y con él su cobardía, nada se puede hacer entre los hombres, nada de valor.

La familia.

Quizás, dado este paso, me atreva a regresar desde las ruinas en las que me alojo desde hace algún tiempo y amar a mis hijos, amarlos con toda la violencia íntima que ese amor merece.

Ahora ya no tengo miedo. Apártense los vivos. (2018: 218)
}

\section{De historia, memoria y literatura}

Por el modo en que está construida la narrativa, podemos observar que trabaja a partir de tres ejes discursivos, que se complementan e interpelan en un mismo relato: la historia, la memoria, y la literatura.

La novela representa un proceso de búsqueda de datos históricos, de acontecimientos, que son de difícil acceso, que han sido olvidados o borrados del relato desde el que se parte, de los conocimientos que tiene Cristina antes de iniciar la investigación $y$, asimismo "pasajes ausentes en el discurso historiográfico hegemónico que nos ha sido transmitido" (Soldevila Durante y Lluch-Prats, 2006: 35). El ejemplo más claro de ello es el de los acontecimientos relativos al asesinato de Félix Fallarás. Además, se representa un diálogo entre la historia en el sentido más factual, los acontecimientos sucedidos en el pasado, y el relato o discurso histórico. Una distinción de la que la novela hace partícipe, explícitamente, al lector. Parafraseando a la 
protagonista de la novela, la historia no puede cambiar, pero sí su relato (Fallarás, 2018: 194). Es decir, es imposible cambiar lo que sucedió, que Félix Fallarás y tantos otros fueran asesinados injustamente, pero sí puede cambiar la forma de contar esos hechos. Implícitamente, se nos remite a la contraposición entre el discurso dominante o hegemónico frente al relato o la visión de los vencidos, "otorgándoles así la voz que el régimen les intentó arrebatar y reivindicando su presencia [...] en la configuración del relato histórico" (Sánchez Zapatero, 2016).

Por otro lado, y aunque íntimamente relacionado con la construcción de un relato sobre la historia, está el eje de la memoria. Sobre él, cómo esta se maneja y qué usos se hace de ella son algunas de las preguntas que podemos plantearnos. Como la misma protagonista reflexiona, la memoria familiar es una vía de acceso a la historia que puede contener un discurso falseado, lleno de ausencias, o que aboga por silenciar el de otros. En ese sentido, la necesidad de hacer un ejercicio de memoria, de no olvidar nuestro pasado, en la obra se propone como un elemento fundamental para construir nuestra propia identidad aun desde la actualidad.

El tercer eje nos conduce de nuevo a repensar lo literario, lo ficcional, filtro a través del que se trabajan los otros dos. En apartados anteriores se ha hablado de autoficción y docuficción y, con ello, de los usos literarios de las novelas de este tipo. Si bien la literatura proporciona un lugar de enunciación mucho más abierto y flexible que otros géneros textuales, no debemos tampoco perder de vista ese filtro de lo ficcional que está presente en las obras. Sin confundir lo ficticio con lo falso ni lo extraficcional con lo verdadero, volvemos al problema de la representación literaria, que en estos casos Alberca criticaba al decir: ‘¿No será que se prefiere el manto protector de la ficción y su declaración expresa de no responsabilidad antes que arrostrar las molestias y el riesgo de contar sin máscaras lo que era hasta entonces privado, secreto, desconocido?' (2007: 77).

Para trabajar con Honrarás a tu padre y a tu madre (2018) en relación con otras novelas similares es necesario apuntar que esta no es exactamente una novela de investigación en el sentido en que las estudia José Martínez Rubio (2015 y otras). Como se ha expuesto con anterioridad, en el texto no se 
reproduce apenas el proceso de investigación, sino que se trabaja a partir de sus resultados. Sin embargo, sí pueden encontrarse algunos rasgos propios de una narración vehiculada por el proceso investigador, y en concreto del género policial. La crítica, con trabajos como los de Sánchez Zapatero (2011b), ha relacionado en ocasiones la novela de investigación autoficcional con este género literario, sobre todo por lo relativo a uno de sus actantes fundamentales: el detective. Se trata de relatos que quedaran estructurados a través de una indagación que concluirá en desvelamiento (Oleza, 1996: 11; 2012: 207). Podría decirse, suscribiendo las palabras de Sánchez Zapatero (2011b), que

\begin{abstract}
Además del sometimiento a las mismas estructuras de indagación, el grupo de novelas del que nos venimos ocupando tiene también en común con el género policial su voluntad de convertirse en crónica, por cuanto se ocupa de un fenómeno de inaudible importancia en la sociedad actual -generador, incluso, de debates en la esfera pública, y su tratamiento de una serie de temáticas relacionadas con la violencia, bien con la institucional propugnada por el gobierno del régimen franquista, bien la personal que infringieron miles de españoles en el contexto de la guerra y la dictadura. No hay que olvidar que, desde sus orígenes, la novela negra se ha caracterizado por su voluntad de reflejar fidedignamente y desde un prisma crítico lo acontecido en la sociedad y, de forma especial, por mostrar de qué modo la violencia está presente en su constitución $y$, que, de hecho, son muchas las interpretaciones que en la actualidad vinculan este género con la literatura social.
\end{abstract}

Con ello, cobra más sentido aún considerar la presencia de ciertos rasgos del género en esta novela de Fallarás, sin olvidar que, por otro lado, se trata de un género cultivado por la autora en obras anteriores como Las niñas perdidas (2011) o Así murió el poeta Guadalupe (2009). Así, encontramos también elementos relativos a él en la disposición del relato, no tanto por lo que concierte a la investigación de la protagonista sino más bien en lo relativo a la posición del lector, a quien se traslada la mirada indagadora.

\title{
Presencia y ausencia; memoria y olvido. Reflexiones finales.
}

A modo de conclusiones, me resulta operativo y pertinente realizar algunas reflexiones en torno a los conceptos de presencia y ausencia, que considero transversales a la mayoría de elementos de la novela. Podríamos decir, por ejemplo, que Félix Fallarás está ausente en realidad en la obra, pues lo poco que queda de él es el recuerdo de su fusilamiento. Ausente en el sentido más literal pero también en la memoria de su propia familia. El caso de 
Presentación, la abuela paterna, es similar; aunque esté viva, y en ese sentido, no esté tan literalmente ausente como su marido, sí lo está en todos los recuerdos de la infancia de la protagonista dado que, entre otras cuestiones, se la priva de ver crecer a su nieta.

Si prestamos atención a las fotografías que acompañan la lectura de la obra, esos elementos docuficcionales, sí veremos algunas fotografías de esta abuela, pero ninguna de Félix Fallarás; las fotografías que aluden a él representan los llamados por Pierre Nora lieux de mémoire, como la tapia en que fue fusilado o una placa conmemorativa y, sin embargo, ni rastro de su presencia física, de su cuerpo.

Todo lo contrario, ocurre al acudir al otro lado de la familia, el de los vencedores. Con ellos sucede totalmente lo opuesto: ellos están presentes en todos los recuerdos de la protagonista, pero no solo eso. De la lectura se desprende que el acceso a información, a recuerdos, sobre su pasado, es mucho más sencillo; la indagación acerca de ellos es exitosa. Sí aparecen en las fotografías, sí hay información detallada y abundante. En otras palabras, a ellos no se les ha privado de la vida ni de la palabra. Si nos fijamos en el coronel, el abuelo paterno, podemos ver que se le dedica el título de la segunda parte de la obra; es la figura presente por excelencia, más si se la compara con el otro abuelo, Félix.

Esta contraposición entre la presencia de los vencedores frente a la ausencia de los vencidos se ve incluso en los aspectos más formales de la novela. Si contemplamos la primera parte, que habla de Félix Fallarás y de Presentación, veremos que no hay un relato prolongado en el tiempo, no hay datos ni apenas detalles, no hay transcurso lineal de los acontecimientos. Los capítulos que corresponden a esta parte son una recreación del momento del fusilamiento. Ese único dato que se posee, que no ha sido totalmente borrado de la memoria, es el punto de anclaje para la narración, pero no hay mucho más que documentar. La dialéctica entre presencia y ausencia que atraviesa contenido y forma, llega incluso a marcar la dimensión paratextual. Al detenernos en la imagen elegida para la portada, tras la lectura, podemos comprobar que las dos personas que aparecen en ella, un hombre y una mujer, son precisamente María Josefa y el coronel; nada de Presentación, nada, por 
supuesto, de Félix. Sea algo voluntario o un desliz azaroso, es sin duda una imagen simbólica que sintetiza el sentido de la novela.

\section{Bibliografía}

AlbercA, Manuel (2007). El pacto ambiguo. De la novela autobiográfica a la autoficción. Madrid: Biblioteca Nueva.

BECERRA MAYOR, David (2015). La guerra civil como moda literaria. Madrid: Clave Intelectual.

CencAS, Javier [2001] (2015). Soldados de Salamina. Barcelona: Penguin Random House.

Clemot, Fernando (2018). "Cristina Fallarás: 'Si yo no lo hubiera perdido todo no me hubiera puesto a escribir esta novela'", Quimera. Revista de Literatura, pp. 415-415. Recurso en línea: $<$ https://www.revistaquimera.com/2018/07/25/entrevista-cristina-fallarasno-lo-hubiera-perdido-no-me-hubiera-puesto-escribir-esta-novela/> [Fecha de la última consulta: 18/05/2021].

Fallarás, Cristina (2009). Así murió el poeta Guadalupe. Madrid: Alianza.

FALLARÁs, Cristina (2011). Las niñas perdidas. Barcelona: Roca.

FAllarás, Cristina (2013). A la puta calle. Crónica de un desahucio. Barcelona: Planeta.

FALLARÁs, Cristina (2018). Honrarás a tu padre y a tu madre. Barcelona: Anagrama.

LAKOFF, George (2006). No pienses en un elefante. Madrid: Complutense.

LEJEUNE, PHILIPPE [1975] (1994). El pacto autobiográfico y otros estudios. Madrid: Megazul-Endymion.

MARTínEZ RuBio, José (2015). Las formas de la verdad. Investigación, docuficción y memoria en la novela hispánica. Barcelona: Anthropos.

MARTínEZ RuBio, José (2012a). "Del documento como verdad al documento como mentira; apropiaciones de la ficción en la novela española actual". En Sonia Boadas, Félix Ernesto Chávez y Daniel García Vicens (eds.), La tinta en clepsidra. Fuentes, historia y tradición en la literatura hispánica. Barcelona: PPU, pp. 413-421.

MARTíneZ RuBio, José (2012b). "Investigaciones de la memoria: el olvido como crimen". En Hans Lauge Hansen y Juan Carlo Cruz Suárez (eds.). La memoria novelada. Hibridación de géneros y metaficción en la novela española sobre la guerra civil y el franquismo (2000-2010). Frankfurt: Peter Lang, pp. 69-82.

MARTÍNEZ RUBIO, José (2014). "Autoficción y docuficción como propuestas de sentido. Razones culturales para la representación ambigua", Castilla. Estudios de Literatura, n. 5, pp. 26-38.

MuÑoz MolinA, Antonio [1991] (2016). El jinete polaco. Barcelona: Seix Barral.

OlezA Simó, Joan (2012). Trazas y bazas de la modernidad. La Plata, Ediciones del lado de acá.

OlEZA SIMÓ, Joan (1996). "Un realismo postmoderno", Ínsula, 589-590, pp. 3942. Consultado en línea: <https://entresiglos.uv.es/wpcontent/uploads/realpost.pdf $>$ [Fecha de la última consulta: 18/05/2021]. 
OlezA Simó, Joan (1997). "Beatus Ille o la complicidad de historia y novela", Bulletin Hispanique, 98, 2, pp. 363-383. Consultado en línea: https://entresiglos.uv.es/wp-content/uploads/beatus.pdf [Fecha de la última consulta: 18/05/2021].

REISZ, Susana (2016). "Formas de la autoficción y su lectura", Lexis, XL (1), pp. 73-98.

RosA, Isaac [2007] (2014). ¡Otra maldita novela sobre la guerra civil! Barcelona: Seix Barral.

RosA, Isaac (1999). La malamemoria. Badajoz: Ediciones del Oeste.

SÁNCHEZ ZAPATERO, Javier (2011a), "Escritura autobiográfica y traumas colectivos: de la experiencia personal al compromiso universal", Revista de Literatura, vol. LXXIII, n.146, pp. 379-406.

SÁNCHEZ ZAPATERO, Javier (2011b). "Detectives de la memoria: la novela negra como medio de indagación en la historia reciente española", Ciberletras, $26 . \quad$ Consultado en línea: <http://www.lehman.cuny.edu/ciberletras/v26/sanchezzapatero.htm> [Fecha de la última consulta: 18/05/2021].

SÁNCHEZ ZAPATERO, Javier (2013). “¿Hay vida más allá de la autobiografía? Sobre la posibilidad del testimonio en la ficción", Tonos Digital: Revista de Estudios Filológicos, n. $\stackrel{0}{25 .}$

SOLDEVILA DURANTE, Ignacio y LLUCH-PRATS, Javier (2006). "Novela histórica y responsabilidad social del escritor. El camino trazado por Benjamín Prado en Mala gente que camina", Olivar: revista de literatura y cultura españolas, n.ㅇ 8, pp. 33-44.

TSCHILSCHKE, Christian von y SCHMELZER, Dagmar (eds.) (2010). Docuficción. Enlaces entre ficción y noficción en la cultura española actual. Madrid/Frankfurt: Iberoamericana Vervuert.

\section{Referencias audiovisuales:}

- Presentación de Las niñas perdidas en la V Feria Internacional del libro en Azcapotzalco, celebrada entre los días 26 de abril y 4 de mayo de 2014. Grabación del acto disponible en línea: $<$ https://www.youtube.com/watch?v=FgscTkenVvQ> [Fecha de la última consulta: 19/09/2021]. 